\title{
SISTEMAS ALIMENTARES SUSTENTÁVEIS E SAUDÁVEIS: DIÁlOGOS E CONVERGÊNCIAS POSSÍVEIS
}

\author{
Islandia BEZERRA ${ }^{1}$ \\ Natalia Ferreira DE PAULA ${ }^{2}$
}

Resumo: Refletir sobre os diálogos e convergências, bem como sobre as divergências, imbricadas nos sistemas alimentares requer, minimamente, uma compreensão ampliada de todo o emaranhado que o engloba e nos convida a rompermos com as leituras compartimentadas da tríade sociedade-natureza-cultura. A ciência da nutrição historicamente sofre influencias do cartesianismo biológico e para pensar em formação/atuação a partir de olhares ampliados é necessário conhecer as diversidades dos sistemas alimentares e discutir alternativas para o modelo hegemônico. A alternativa é aqui apresentada através da agroecologia, em sua tríade ciência-movimento-prática. A discussão busca romper com a lógica compartimentada, visto que as/os nutricionistas são fundamentais na busca e na construção de sistemas alimentares sustentáveis e saudáveis.

Palavras-chave: Segurança Alimentar e Nutricional; Agricultura Sustentável; Ciência da Nutrição

\section{SUSTAINABLE AND HEALTHY FOOD SYSTEMS: POSSIBLE DIALOGUES AND CONVERGENCES}

\begin{abstract}
Reflecting on dialogues and convergences, as well as divergences, interwoven in food systems requires, at the very least, an expanded understanding of the whole tangle that encompasses it and invites us to break with the compartmentalized readings of the society-nature-culture triad. The science of nutrition historically suffers from the influences of biological cartesianism and to think about training/acting from magnified perspectives it is necessary to know the diversity of food systems and discuss alternatives to the hegemonic model. The alternative is presented here through agroecology, in its science-movement-practice triad. The discussion seeks to break with the compartmentalized logic, since nutritionists are fundamental in the search and construction of sustainable and healthy food systems.
\end{abstract}

Key-words: Food and Nutrition Security; Sustainable Agriculture; Science of nutrition

\footnotetext{
${ }^{1}$ Mulher. Mãe. Pesquisadora. Extensionista e Professora Associada da Faculdade de Nutrição - FANUT/UFAL Educadora Colaboradora na Escola LatinoAmericana de Agroecologia (ELAA). Presidenta Nacional da Associação Brasileira de Agroecologia/ABA (Gestão 2020-2021). Nutricionista. Mestre e Doutora em Ciências Sociais/UFRN. E-mail: islandiabc@gmail.com

${ }^{2}$ Mulher. Mãe. Nutricionista. Especialista em Gestão da Segurança de Alimentos. Mestre em Alimentação e Nutrição pela UFPR. Doutoranda em Políticas Públicas. Professora na UNICURITIBA, na UniCesumar e na UFPR. Faz parte da diretoria executiva da Associação de Nutrição do Paraná - ANUPAR. Integra a Rede Nacional de Pesquisa em Segurança Alimentar e Nutricional e o Grupo de pesquisa Agricultura e Sistemas Agroalimentares - UFPR. E-mail: nataliafesr13@gmail.com
} 


\section{SISTEMAS ALIMENTARIOS SOSTENIBLES Y SALUDABLES: POSIBLES DIÁLOGOS Y CONVERGENCIAS}

Resumem: Reflexionar sobre los diálogos y convergencias, así como sobre las divergencias, entretejidos en los sistemas alimentarios requiere, minimamente, una comprensión ampliada de toda la tela de araña que lo envuelve y nos invita a romper con las miradas compartimentadas de la tríade sociedad-naturaleza-cultura. La ciencia de la nutrición ha estado históricamente influenciada por el cartesianismo biológico y para pensar la formación y actuación desde perspectivas amplias es necesario conocer la diversidad de los sistemas alimentarios y discutir alternativas al modelo hegemónico. La alternativa que se presenta aquí a través de la agroecología, en su tríade ciencia-movimiento-práctica. La discusión busca romper con la lógica compartimentada, ya que los/las nutricionistas son fundamentales en la búsqueda y construcción de sistemas alimentarios sostenibles y saludables.

Palabras clave: Seguridad Alimentaria y Nutricional; Agricultura Sostenible; Ciência de la nutrición

\section{Introdução}

Não há como dimensionar o valor da vida, se não dimensionarmos o valor da própria existência. A vida que pulsa e impulsiona processos sociais, culturais e identitários, biológicos mais especificamente fisiológicos - alinhados com a natureza, passa pelo ato de se alimentar (e alimentar os/as demais). Nestes termos, os sistemas alimentares se converteram na expressão mais intensa e concreta desse ato corriqueiro "do comer" que, apesar de parecer simples, é altamente complexo. Debater sobre Comida de Verdade torna-se então fundamental. Para tanto, referenciamos aqui o Manifesto da $5^{\text {a }}$ Conferência Nacional de Segurança Alimentar e Nutricional ( $\left.5^{\mathrm{a}} \mathrm{CNSAN}, 2015\right)$ que afirma:

[...] a comida de verdade como salvaguarda da vida. [...] é saudável tanto para o ser humano quanto para o planeta. Garante os direitos humanos, o direito à terra e ao território, a alimentação de qualidade e em quantidade adequada em todo o curso da vida. Considera comer como um ato político. Define a Comida de verdade como a que reconhece o protagonismo da mulher, respeita os princípios da integralidade, universalidade e equidade. Não mata nem por veneno nem por conflito. (Manifesto da $5^{\mathrm{a}} \mathrm{CNSAN}$ ).

Por outro lado, ainda em referência à vida, não há como desconsiderar o agravamento do atual quadro de fome pelo qual centenas de milhares de pessoas do Brasil e de outras partes do mundo vem, cotidianamente experimentando. Essa imposição austera vem sendo exacerbada também pela condição pandêmica causada pela SARS-CoV-2 (Síndrome Respiratória Aguda Grave 2), o coronavírus causador da Covid-19, e reflete as indiferenças e o desdém de um sistema alimentar de produção industrial que se pauta apenas nos princípios do lucro acima de tudo que pouco se importa com a saúde, nem das pessoas que fazem parte desses sistemas, nem mesmo da natureza que segue sendo explorada em todas as dimensões negativas do termo.

Refletir sobre os diálogos e convergências, bem como sobre as divergências, imbricadas nos sistemas alimentares requer, minimamente, uma compreensão ampliada de todo o emaranhado 
que o engloba e nos convida a rompermos com as leituras compartimentadas da tríade sociedadenatureza-cultura. A ênfase aqui colocada é na alimentação e nutrição, sobretudo se a perspectiva do refletir-agir estiver alinhada aos princípios e diretrizes, que em alguma medida, concretiza no cotidiano a Soberania e Segurança Alimentar e Nutricional/SSAN dos povos.

É com esse objetivo que esse texto traz o desafio de elencar algumas questões que possam contribuir nessa feitura. A partir das análises dos sistemas alimentares - e aqui vale à pena mencionar que tratamos da pluralidade da terminologia "sistemas" já que partimos do pressuposto que o plural dos "sistemas" engloba dimensões múltiplas que passam pelas questões históricas, ambientais, sociais, culturais, simbólicas, econômicas e políticas, nas quais pesam questões práticas e cotidianas do comer e nutrir como a produção e consumo conscientes (ou não), nutricionalmente adequados (ou não), culturalmente referenciados (ou não), eticamente comprometidos (ou não) com as questões ambientais, geracionais, raciais/étnicas, de classes sociais e de gênero.

É sob essa ótica complexa (e de certo modo, superficial, já que não temos o espaço necessário para maiores aprofundamentos) que desenvolvemos esse texto. Longe de esgotarmos o debate temos a pretensão de apenas disparar processos reflexivos e, quem sabe, transformadores dos sistemas alimentares - que atualmente expressam destruição e opressão -, para algo construtivo, harmônico e libertador.

A primeira sessão Sistemas alimentares sustentáveis e saudáveis uma compreensão a partir da Ciência da Nutrição evidencia a necessidade de compreender como e por que esses sistemas assumem tal diversidade, considerando questões para além da alimentação e da nutrição, refletindo sobre a conexão dos sistemas alimentares com a lógica política e econômica global que por sua vez, reverbera no regional-local.

A segunda sessão A agroecologia que dialoga e converge para construção de sistemas alimentares sustentáveis e saudáveis explora de forma mais explícita que, ao tomar por base os princípios da Agroecologia - Ciência, Movimento e Prática - os diálogos e convergências são reais, possíveis e porque não dizer, necessários.

A centralidade dos temas alimentação e nutrição como consequências diretas dos sistemas alimentares sustentáveis e saudáveis, fazem parte de um conjunto de outras complexas questões que, por sua vez, conectam as dimensões da saúde (das pessoas e do ambiente). Assim, estimular processos que tragam na sua essência as dimensões da sustentabilidade e da saudabilidade da produção e consumo de alimentos, mais também de significados simbólicos do ato de se alimentar (e alimentar os/as demais) nos territórios é, portanto, a recomendação primeira posta no final desse artigo. 


\section{Sistemas alimentares sustentáveis e saudáveis uma compreensão a partir da Ciência da} Nutrição

O Sistema Alimentar é definido como um agregado econômico de diversas atividades, traduzido pelo encadeamento lógico de vários setores, que vão desde a produção até o consumo de alimentos, setores esses que se articulam para promover a produção e abastecimento de alimentos em escala local e mundial (DAVIS; GOLDBERG, 1957; MULLER, 1989; PAULA, 2017; GRUPO ETC, 2019). Nesse contexto estão envolvidas basicamente:

1. As empresas que produzem e comercializam insumos agrícolas (maquinários, sementes, agrotóxicos, fertilizantes, adubos químicos, entre outros), que por sua vez detém a tecnologia destes produtos, por meio das patentes;

2. O setor agropecuário, que efetivamente produz os alimentos, constituído pelos camponeses e agricultores familiares, agricultores empresariais e agricultores capitalistas $^{3}$ (PLOEG, 2008).

3. A indústria de transformação de alimentos, desde multinacionais oligopolistas, até pequenas agroindústrias;

4. O setor de distribuição, no caso brasileiro as nominadas Centrais de Abastecimentos (CEASAs), bem como as grandes redes varejistas tais como os hiper e supermercados e também, em alguma medida as mercearias e/ou pequenos estabelecimentos.

5. A aquisição, preparo e o consumo de alimentos, mais especificamente formado pelos consumidores e consumidoras.

Nestes termos, é fundamental trazer à tona o debate sobre o papel e/ou a influência que incide a ciência da nutrição nesse sistema alimentar de produção industrial. Pode-se dizer que esta se insere no âmbito do sistema alimentar em diferentes níveis e suscita atenção especial para o setor de transformação, distribuição e recomendação do consumo de determinados produtos e/ou alimentos.

A Nutrição como ciência se localiza de forma evidente (e inquestionável) no campo da saúde possuindo assim - no processo da formação profissional -, influencias históricas de uma orientação que determina e define o perfil dos profissionais de saúde, no qual o modelo biológico cartesiano, centrado no processo curativo e na atuação com base em especialidades é o que caracteriza a prática profissional. Certamente, essa orientação dificulta o olhar do e para o indivíduo como um ser integral que se insere - influenciando e sofrendo influências do ambiente

\footnotetext{
${ }^{3}$ Ploeg (2008) em sua obra "Impérios Alimentares" classifica os agricultores dessa forma, atribuindo características específicas para cada um desses, que por sua vez relacionam-se com o sistema alimentar imperial (denominação do autor para o terceiro Regime Alimentar).
} 
que ocupa - interferindo assim em uma análise mais complexa e ampliada do processo saúdedoença (AMORIM; MOREIRA; CARRARO, 2001). No entanto, atualmente cada vez mais as instituições de educação/formação, bem como entidades de nutrição e nutricionistas reconhecem a necessidade de ir além do biológico, considerando as dimensões ambiental, cultural, econômica, política, psicoafetiva, social e simbólica na atuação profissional, pautando uma formação/atuação profissional que desperte o senso crítico-reflexivo-transformador (CFN, 2018).

Outra questão importante na formação e atuação do/da nutricionista é a transdisciplinaridade e a interdisciplinaridade, que a partir da busca por resgatar e/ou conectar suas/nossas raízes culturais e filosóficas são essenciais para uma prática profissional que priorize o refletir-agir-transformar colaborando assim para uma transformação social (e alimentar) (CALÇAS et al., 2016, grifos nosso). Diante do exposto reconhecer e compreender as diversidades intrínsecas aos sistemas alimentares e seus determinantes, relacionando as mesmas com os contextos histórico, político e econômico a nível global e local é importante para um olhar diferenciado às questões relacionadas a alimentação e a nutrição. Importante considerar aqui, que para essa análise aprofundada é necessário buscar autores/as de outras áreas, como a sociologia, a economia, a história, as políticas públicas, a agroecologia, entre outros pertinentes aos sistemas alimentares que prezem pela sustentabilidade e saudabilidade.

Nesse sentido, iniciamos a análise da diversidade dos sistemas alimentares, a partir das influencias históricas e sua mutação através dos tempos. Para tratar desse assunto não poderíamos deixar de abordar a teoria dos Regimes Alimentares, uma vez que esta ideia periodiza os sistemas em três diferentes Regimes ao longo dos tempos, nesse preceito as autoras e os autores distinguem o sistema alimentar em primeiro, segundo e terceiro Regime Alimentar.

Ao longo desses três Regimes, o sistema alimentar adquire uma relação diferente com a ordem mundial, apresentando características predominantes articuladas para sustentar a hegemonia do determinado período histórico (PAULA, 2017). Dessa forma, no primeiro Regime que data do final do século XIX à 1930, a ordem se deu para manter a hegemonia britânica, o qual foi marcado pelo intercâmbio comercial de alimentos entre a Grã-Bretanha e seus estados coloniais.

O segundo Regime ocorreu após a segunda Guerra Mundial e a década de 1970, sustentando a hegemonia dos Estados Unidos, através de suas práticas de exportação de excedentes e dos programas de ajuda alimentar. Já o terceiro e atual Regime Alimentar, iniciou na década de 1970 e é marcado pela globalização, financeirização e hegemonia de Impérios Alimentares, formados por grandes corporações oligopolistas do sistema alimentar, ligadas ainda a hegemonia dos Estados Unidos (McMichael, 2016). 
Por esse motivo, esse Regime é denominado de Regime Alimentar Contemporâneo por Friedmann (1993), Corporativo por McMichael (2016), Imperial por Ploeg (2008) e Neoliberal por Pechlaner e Otero (2010). Importante destacar que os três Regimes Alimentares estão inseridos e agem de acordo com a lógica política e econômica de seu momento, dessa forma pode-se dizer que o sistema alimentar é moldado para propagar e sustentar o regime econômico/político hegemônico e desencadeia processos complexos na sociedade, sobretudo, no âmbito da alimentação e nutrição, porém, não somente. Sabe-se que fatores associados à destruição ambiental - em essência - é uma característica forte e presente no Regime atual.

O terceiro Regime Alimentar, portanto, é considerado um braço do sistema capitalista neoliberal que vigora de forma hegemônica no mundo atual, e dessa forma assume características próprias desse ordenamento (McMichael, 2016; PECHLANER; OTERO, 2010).

Assim, algumas características do terceiro Regime Alimentar são a concentração de poder, de capital, dos meios de produção e processamento de alimentos, além da centralização de desenvolvimento de tecnologia, por parte das corporações transnacionais do setor de agroinsumos, transformação e distribuição de alimentos (McMichael, 2016). Esta hegemonia do terceiro Regime é denominada - Impérios Alimentares - por Ploeg (2008), segundo o autor o Estado também é um ator importante dessa organização, uma vez que o mesmo é cooptado pelas corporações, que o utilizam a seu favor, principalmente a partir dos lobbys (lobistas) que manipulam as regulamentações (criações de normas, leis, decretos) e impulsionam a maximização do lucro de proprietários e acionistas, possibilitando assim uma máxima exploração da força de trabalho de mulheres e homens, precarizando relações trabalhistas, reduzindo salários entre outras perdas. Nesse cenário, a natureza, por sua vez também sofre as consequências desse modelo como, por exemplo, as mudanças climáticas que estão conectadas aos processos de desmatamentos, contaminação e destruição ambiental de toda ordem.

Marion Nestle, em sua obra "Uma verdade indigesta" (2019) desvela ainda a relação entre a comida, a pesquisa no âmbito da ciência da alimentação e da nutrição e as relações de poder na sociedade. A autora demonstra, a partir das evidências, o quanto esse meio é influenciado pelas corporações que controlam o sistema alimentar neoliberal. Portanto, a construção da ciência, bem como das narrativas do que é saudável e sustentável no âmbito do sistema alimentar, também é uma área constantemente tencionada pelas corporações do sistema alimentar imperial/neoliberal. Essa constatação reitera, portanto, a necessidade de investirmos em uma formação de nutricionistas, bem como uma atuação desses/dessas profissionais de forma ainda mais críticareflexiva e, fundamentalmente, transformadora. 
Essa concentração do sistema alimentar neoliberal, promove um processo que vem sendo denominado por mercantilização dos alimentos, o qual coloca o alimento (a comida) única e exclusivamente como uma mercadoria. Esse processo propicia o distanciando e, porque não dizer, uma desconexão cada vez mais presente e intensa nas relações imbuídas entre quem produz e quem consome (alimentos e comida). Ademais, contribui também para a extinção dos alimentos e/ou preparações regionais, expropriando de forma fácil e simples a cultura alimentar dos povos, e transforma os alimentos em formulações comestíveis altamente promovidas por publicidade e propaganda, projetadas para elevar ao máximo os lucros e atender ao mercado financeiro impaciente que financia as corporações alimentícias (PLOEG, 2008; POULAIN, 2013, grifo nosso).

Como resultado desse processo, se tem o consumo desenfreado de produtos ultraprocessados (não saudáveis), produzidos com insumos químicos, que são introduzidos, desde o campo até a mesa, além de grandes quantidades de açúcar, sódio, gorduras industriais, baixas quantidades de micronutrientes, fibras e compostos bioativos (OPS, 2019, grifo nosso). Nesse contexto, o alimento, ou não alimento como refere Ploeg (2008), se torna um bem de consumo como qualquer outro, produzido e comercializado pelas corporações para atender o público consumidor.

Por conseguinte, outra característica presente nesse sistema alimentar neoliberal é a desigualdade, visto que o acesso a bens de qualidade (e aqui o alimento é visto como uma mercadoria, portanto um bem) é limitado às pessoas que possuem capital para adquiri-los. Essa desigualdade de acesso ao capital é refletida então no acesso aos alimentos, sobretudo alimentos de qualidade, ou seja, comida de verdade.

Em consonância a essa lógica, a FAO tem redefinido o conceito sobre a manifestação da insegurança alimentar, onde não somente o acesso de alimentos é importante, mas aquelas e aqueles que não possuem acesso a alimentos nutricionalmente adequados também são consideradas pessoas em situação de insegurança alimentar e nutricional (FAO, 2020). O conceito brasileiro de Segurança Alimentar e Nutricional (SAN) traz outras dimensões a saber é “... o acesso regular e permanente a alimentos em quantidade e qualidade suficiente, sem comprometer o acesso a outras necessidade essenciais" e desde a sua criação tem sido considerado um conceito amplo de SAN, que além de abordar a qualidade da alimentação como uma questão prioritária, abrange também questões como a diversidade cultural e a sustentabilidade nos seus aspectos ambiental, cultural, econômico e social (BRASIL, 2006).

Entretanto, atender o conceito de SAN em sua totalidade de forma universal no sistema alimentar neoliberal é quase que uma utopia, pois como mencionado anteriormente, esse sistema 
hegemônico, estabelece uma lógica que promove doença (das pessoas e do ambiente) e que destrói a agrobiodiversidade e a cultura alimentar. $\mathrm{O}$ resultado desse ordenamento vem sendo discutido por Swinburn et al. (2019) que traz a referência da sindemia global, onde os fenômenos pandêmicos da obesidade, da desnutrição e das mudanças climáticas são sinérgicos entre si, fomentando umas as outras de forma mútua e complexa.

Entretanto, é importante destacar aqui, que esse impacto acomete desproporcionalmente às vidas das pessoas, um movimento "normal" do sistema capitalista. Isso porque os segmentos sociais menos privilegiados pelo sistema (e aqui consideramos as questões interseccionais de gênero, raça/etnia e classe social) são também, os mais atingidos pela desnutrição, obesidade, sobrepeso e doenças crônicas não transmissíveis (SWINBURN et al., 2011; OTERO, et al., 2015). Para se referir a essa desigualdade, Freeman (2007) usa o termo "opressão alimentar", ao reportar o conjunto de fatores que expõe desigualmente as comunidades afro-americanas e latinas dos Estados Unidos ao consumo de fast-food em detrimento aos alimentos saudáveis.

No Brasil temos alguns dados empíricos bem importantes para ilustrar essa questão, podemos elencar aqui a última pesquisa de orçamento familiar (POF) realizada em 2017-2018 sobre segurança alimentar e nutricional, a qual revelou maiores índices de insegurança alimentar grave em domicílios chefiados por mulheres (IBGE, 2020a). Assim como a prevalência de obesidade que acomete em maior proporção as mulheres, bem como as pessoas com graus inferiores de escolaridade que, além do sobrepeso e obesidade, também apresentam maiores índices de doenças crônicas não transmissíveis causadas pela má alimentação, como diabetes e hipertensão (BRASIL, 2020). Essas constatações ganham destaque quando se faz o recorte de raça/etnia. São as mulheres negras que se localizam nos piores patamares que trazem as dimensões da alimentação, nutrição e saúde.

No ano de 2018, $86 \%$ da população de 0 a 8 anos de escolaridade estavam em estado de sobrepeso ou obesidade, enquanto entre aquele(a)s com escolaridade de 12 anos ou mais, esse percentual era de $67 \%$, o que corresponde a uma diferença de aproximadamente 20 pontos percentuais (BRASIL, 2019). Esses dados corroboram os achados de Devaux et al. (2011) em pesquisa realizada na Austrália, Canadá, Inglaterra e Coreia, segundo a qual as pessoas com menor tempo de estudo apresentaram maiores índices de obesidade. Esses resultados refletem a distinção perpetuada pelo sistema alimentar neoliberal, onde existe uma limitação do consumo de alimentos saudáveis pela população mais vulnerável, e ao mesmo tempo um aumento do consumo de alimentos ultraprocessados (IBGE, 2020b).

A POF também constatou que a aquisição domiciliar per capita anual de frutas em domicílios brasileiros, demonstrou uma diferença muito expressiva, chegando a $313 \%$ quando se 
faz a distinção de classes (IBGE, 2020b). Esta disparidade também é demonstrada para aquisição domiciliar per capita anual de hortaliças, a qual chega a uma diferença de $187 \%$ quando comparadas as mesmas faixas extremas de rendimento total e variação patrimonial mensal familiar (IBGE, 2020b). As frutas, legumes e hortaliças, que por sua vez são classificadas como alimentos in natura são recomendados pelo Guia Alimentar para a População Brasileira para se constituírem a base para se ter uma alimentação saudável (BRASIL, 2014).

Contudo, a grande questão dos sistemas alimentares hegemônicos atuais é a concentração de poder dos Impérios Alimentares ${ }^{4}$, a qual promove destruição da natureza e gera desigualmente ambientes e condições que promovem doenças relacionadas a má alimentação, por meio de disponibilidade e acesso limitados a comida de verdade e outras necessidades essenciais. Essa privação, provém das desigualdades impostas pelo sistema capitalista, que o sistema alimentar neoliberal reproduz, fortalece e perpetua enquanto modelo hegemônico de organização política e econômica, que por sua vez retroalimenta e sustenta o sistema capitalista, suscitando um ciclo vicioso que precisa ser rompido para se vislumbrar sistemas alimentares sustentáveis e saudáveis.

Pechlaner e Otero (2010), analisam a relação dos países desenvolvidos e subdesenvolvidos no sistema alimentar neoliberal, e levantam algumas questões importantes, como a divisão internacional do trabalho, onde os países do sul do mundo produzem produtos que não são de primeira necessidade para alimentar as nações, como grãos para alimentação animal e agrocombustíveis, vinhos e frutas especiais e ao mesmo tempo importam alimentos de primeira necessidade, dependendo dos países desenvolvidos para itens básicos da alimentação, o que influencia diretamente na soberania alimentar dos povos. Importante ressaltar aqui que nesses países o modelo convencional de produção agrícola pautado no pacote verde, baseado em monoculturas químico-dependentes é também explorado de forma diferenciada dos países desenvolvidos, visto que além da divergência entre os tipos de produtos cultivados, conforme apontado acima, contam ainda com modelos de exploração da natureza mais severos, isso pode ser verificado por exemplo pela quantidade e os tipos de agrotóxicos utilizados e liberados para o uso.

O Brasil, por sua vez, é o país que mais consome agrotóxicos em todo o mundo desde 2008 e a cada dia possui mais tipos de venenos liberados para o cultivo de produtos agrícolas (ABRASCO, 2015). O que demonstra a permeabilidade das corporações de insumos agrícolas nas

\footnotetext{
${ }^{4}$ Império alimentar é um termo cunhado por Ploeg (2008) para uma estrutura composta por esquemas reguladores de natureza política e econômica que são impostos à sociedade e à natureza. Essas estruturas são formadas por corporações em conjunto com o Estado, bases dos Impérios Alimentares, identificadas nos grupos do agronegócio, grandes varejistas, mecanismos estatais, conjuntos de normas, modelos científicos, tecnologias, entre outros que dominam o Sistema Alimentar no âmbito do terceiro Regime Alimentar.
} 
regulamentações brasileiras. Um exemplo dessa regulamentação manipulada é a política brasileira de desoneração fiscal de agrotóxicos, que é extremamente atrativa, visto que os incentivos vão desde a isenção do PIS/Cofins e do IPI, até a cobrança de apenas 60\% do ICMS (a depender de políticas estaduais que podem aumentar as isenções) (ABRASCO, 2015; ODEVEZA, 2019).

Odeveza (2019) refere ainda que um dos impactos desses incentivos fiscais é a abdicação de vultuosos recursos dos cofres públicos que poderiam ser investidos em políticas sociais, sem considerar que essas regulações incentivam o uso desses produtos, aumentando ainda mais o adoecimento da população e os gastos públicos com tratamento de doenças crônicas e intoxicações agudas advindas desse modelo.

Corroborando estes estas constatações Soares e Porto (2012) ilustram esse fato ao apontar que o custo com intoxicações agudas por agrotóxicos podem chegar a US $\$ 149$ milhões no estado do Paraná e revelam ainda que, para cada dólar gasto em agrotóxicos no estado, US\$1,28 é gasto com custos externos para tratamento de intoxicação - por agrotóxicos - isso sem contar os gastos do Sistema Único de Saúde (SUS) com determinadas doenças crônicas que por sua vez, possuem uma intrínseca relação com o resíduo de agrotóxicos em níveis celular, levando ao surgimento de diferentes tipos de cânceres.

Ademais, de acordo com a Secretaria da Fazenda de São Paulo somente a renúncia físcal de ICMS dos agrotóxicos no estado somou R \$1,2 bilhão no ano de 2015. Odeveza (2019) chama atenção ao comparar esse valor com o orçamento designado para a Secretaria de Agricultura e Abastecimento do mesmo estado no ano de 2016, que foi de R $\$ 1,1$ bilhão, ou seja, valor menor do que o deixado de arrecadar com agrotóxicos (somente em relação ao ICMS) no ano anterior.

Outra questão identificada por Pechlaner e Otero (201) é a resistência ao sistema alimentar neoliberal, que tem sido mais presente e intensa nos países mais afetados pelo sistema, ou seja, os países subdesenvolvidos e em desenvolvimento. Pra tanto citam a experiência do México, que é diretamente impactado pelo NAFTA (Acordo de Livre Comércio da América do Norte, composto por Canadá, Estados Unidos e México). Nesse acordo, o México é o país que mais sofre as consequências das políticas neoliberais e, consequentemente, do sistema alimentar. Ao longo dos últimos anos, México vem disparando processos de resistências ao sistema que reverberam em outros países da América Latina e Caribe. Mediante as ações da sociedade civil organizada várias organizações e coletivos sociais impulsionaram (e ainda impulsionam) estratégias que possam contribuir para a criação e/ou manutenção de sistemas alimentares mais sustentáveis e saudáveis. Exemplos concretos destes movimentos é a campanha "Sin Maiz, No hay Pais" ou o mais recente movimento "ley antichatarra" que resultou em mudanças significativas normatizando, por 
exemplo o comércio de produtos ultraprocessados - no México se conhece por "junk foods"- no entorno de creches e escolas.

Dessa forma, percebe-se que o sistema alimentar se reorganiza e assume características próprias em diferentes países, que podem ser compreendidas também no âmbito dos estados e das cidades, importante considerar que essa organização local está inserida e portanto não desconectada, do processo global, mas é possível encontrar inúmeras conformações e iniciativas contra hegemônicas nos chamados "microssistemas alimentares" locais.

Nesse sentido apresentamos algumas questões sobre a busca de novos sistemas alimentares, que sejam sustentáveis e saudáveis. McMichael (2006), Ploeg (2008) e Friedmann (2005) elencam a descentralização dos sistemas alimentares como prioridade para transformação dessa realidade.

Contudo ressaltamos aqui que a descentralização por si só não é suficiente. É imprescindível que ela esteja articulada com outras ações e iniciativas sistêmicas e de cunho estrutural como a redistribuição de terras, taxação de agrotóxicos e demais insumos químicos, o estímulo à agricultura de bases agroecológicas, incentivos e intervenções no campo das políticas públicas voltadas para produção, distribuição, comercialização, acesso e consumo de alimentos agroecológicos. Sabendo dos limites, especialmente, no que diz respeito ao acesso aos alimentos agroecológicos, nos cabe investir e potencializar processos que culminem na transição agroecológica, associando a isso ao incentivo do consumo de alimentos in natura, minimamente processados e culturalmente referenciados, bem como a ampliação da disponibilidade e acesso de comida de verdade no campo e na cidade.

Outras alternativas em curso em diferentes países, especialmente no continente latino americano, e que em alguma medida converge para a criação de sistemas alimentares sustentáveis e saudáveis, dizem respeito às outras dimensões do campo de atuação do sistema alimentar neoliberal. Como exemplo, citam-se: as medidas de controle da publicidade e propaganda dos produtos ultraprocessados, a taxação de formulações alimentícias prontas para o consumo e, ainda, as normativas (leis e/ou decretos) que obrigam as indústrias do setor a disponibilizar informações claras nos rótulos dos alimentos, especialmente sobre as substâncias nocivas à saúde. Estas e outras ações vem sendo pautadas, sobretudo, pela sociedade civil organizada, instituições, organizações e/ou coletivos no campo da alimentação e nutrição, cuja atuação tem sido fundamental para transformar a lógica hegemônica atual.

Reiteramos ainda, que nessa arena - de e para a construção de sistemas sustentáveis e saudáveis - é necessário um investimento humano. Não um humano descolado da natureza, mas como parte dela e que precisa dela. Nestes termos a Ciência da Nutrição precisa ocupar um lugar 
que paute uma formação ética, crítica, reflexiva e transformadora do/da nutricionista. Que tome ainda como referência toda a complexidade imbuída na inter-trans-disciplinaridade e também na intersetorialidade, quando partimos para a prática profissional. Não apenas, por serem profissionais, mas como sujeitos e sujeitas que podem/devem fazer parte das mudanças necessárias.

\section{A agroecologia que dialoga e converge para construção de sistemas alimentares sustentáveis e saudáveis}

A agroecologia, a partir do seu tripé Ciência-Movimento-Prática impulsiona processos do refletir-agir-transformar e promove a construção de sistemas alimentares sustentáveis e saudáveis se apresentando, portanto, como resposta para concretizar a Soberania e Segurança Alimentar e Nutricional/SSAN. Para Clara Nicholls (2020, p. 07) a Agroecologia se apresenta como sendo outra ciência, vez que esta é capaz de disparar “...processos de inovação cognitiva, tecnológica e sociopolítica”. Já para Schmitt e colaboradores (2018, p. 52):

A construção da agroecologia encontra-se vinculada a um amplo projeto de transformação das formas de produção, processamento, distribuição e consumo presentes no atual sistema agroalimentar. Seus princípios e práticas possuem uma longa trajetória de enraizamento nos modos de vida dos camponeses e camponesas, povos indígenas e comunidades tradicionais nas mais diferentes partes do mundo. Suas bases seguem os princípios de justiça social, sustentabilidade ambiental e soberania alimentar, assumindo compromisso político com a democratização do direito à terra, à água, aos recursos naturais e às próprias estruturas de produção do conhecimento (grifo nosso).

Corroborando dessas assertivas, Lilian Telles (2018) aponta que a diversidade sociocultural e política da agricultura familiar e camponesa, bem como da agricultura urbana e também dos povos e comunidades tradicionais é a base que constrói o conhecimento agroecológico e por esse motivo suas tessituras envolvem redes/coletivos e movimentos sociais que se alinham com as instituições de ensino, pesquisa e extensão e potencializa a construção do conhecimento agroecológico.

No Brasil é possível demarcar - quando e quem - contribuiu (e segue contribuindo) para os avanços da construção do conhecimento agroecológico. Para Burigo e Porto (2020) em 2002 a criação da Articulação Nacional de Agroecologia/ANA e em 2004 a criação da Associação Brasileira de Agroecologia/ABA-Agroecologia puseram em marcha e alavancaram os processos dessa construção. É possível afirmar que a partir de então essas redes se fortaleceram em diferentes territórios como nas aldeias indígenas, comunidades quilombolas, comunidades rurais, urbanas e peri-urbanas e, sobretudo nos mais longínquos rincões do Brasil. Certamente as conquistas nesse campo também se deve às inúmeras parcerias firmadas com os movimentos sociais de base, que 
por sua vez pautam além da Agroecologia, outras bandeiras que dialogam e se conectam aos princípios da justiça social e ambiental.

Convém mencionar, no entanto, que alguns estudos trazem análises de autores e autoras alertando para o cenário de que existe uma tendência para uma melhor aceitação, bem como para uma maior adoção de sistemas agroecológicos (ou que optam pela transição agroecológica) frequentemente equivocados e estão associados à uma perspectiva reducionista de que o mundo deve produzir mais alimentos com o intuito de suprir a crescente demanda global de alimentos, que, diga-se de passagem 'estilo ocidental' projetando assim, um acréscimo de $60 \%$ na produção de carnes e seus derivados em 2050, quando comparado a 2006 segundo Alexandratos e Bruinsma (2012). Constata-se nesse argumento superficial e simplista, que outras dimensões profundas e complexas são intencionalmente negligenciadas. Certamente, existem outras variáveis que precisam ser consideradas, por exemplo a que questiona o acesso da população global a que tipo de alimentos? (ou não alimentos?) como alguns são considerados.

É possível inferir que, de fato, existem nuances que distorcem e desconectam os princípios da Agroecologia à concepção da Comida de Verdade e, por conseguinte da SSAN. O que temos em curso são cenários/arenas de disputas econômicas e, sobretudo políticas, que fortalecem, aprofundam e perpetuam as desigualdades sociais e acentuam, cada vez mais mediante o implemento de altas tecnologias, em níveis jamais vistos, a exploração e a expropriação da natureza.

Segundo o recém documento publicado pelo Banco Mundial (2020) - Panoramas alimentarios futuros. Reimaginando la agricultura en América Latina y el Caribe -, existe por parte desta instituição, o reconhecimento de que a América Latina e Caribe/ALeC se transformou na principal região do planeta com produção de alimentos capaz de suprir o abastecimento não apenas para a região, mas também para o mundo. Ao mesmo tempo, essa região é também a maior responsável por prover ao mundo "serviços ecossistêmicos" imensuráveis, ou seja, a região possui ecossistemas capaz de fornecer às pessoas e ao ambiente (com sua fauna e flora) o bem estar e o conforto necessários para viver, mas também à agricultura o incremento na sua produtividade. A ALeC possui uma cobertura significativa de vegetações nativas, além de ser o centro de origem de $40-50 \%$ da biodiversidade mundial (BANCO MUNDIAL, 2020). No entanto, o documento evidencia também que os sistemas alimentares que são impulsionados na região trazem elevados custos para a saúde das pessoas e do ambiente. Em que pese toda as riquezas naturais, estas vem sendo constantemente destruídas pelas distintas formas de ataque dos sistemas alimentares (ou não), como queimadas dos biomas (floresta amazônica, mata Atlântica, cerrado, caatinga, 
pantanal), grandes projetos como mineração, barragens, estradas entre outros “... já que estes se apresentam como potenciais ameaças aos bens públicos” (p. 08).

Conforme visto no tópico anterior são estes sistemas alimentares hegemônicos que destroem a natureza e que possuem uma relação direta com elevados índices de prevalência e incidência das chamadas doenças relacionadas à má-nutrição sendo, portanto, prejudiciais para a saúde das pessoas. Louzada e colaboradores (2019) evidenciaram estas relações a partir de uma extensa e providencial pesquisa em artigos científicos produzidos em diversos países do mundo e, por sua vez, reiteraram a importância da Classificação NOVA adotada pelo Guia Alimentar para a População Brasileira.

Ainda em 2019, a Comissão Lancet que compõem um renomado periódico científico The Lancet usou o termo "Sindemia" para explicar a associação, em escala global considerando o tempo e o espaço, três fenômenos pandêmicos: obesidade, desnutrição e mudanças climáticas. Segundo esta comissão “... suas causas passam pelos interesses comerciais que orientam o modelo hegemônico do sistema agroalimentar global".

Para Veiga-Neto (2020, p. 09) o termo sindemia “... é um neologismo bastante útil para nos referirmos à combinação e potencialização de problemas que se situam nos âmbitos sanitário, sociocultural e ambiental". Este autor traz a referência histórica de quando e porque o termo surgiu. Segundo ele, foi na década de 1990 quando o médico-antropólogo Merril Singer criou o termo sindemia para designar as combinações sinérgicas entre a saúde de uma população e os respectivos contextos sociais, econômicos e culturais (VEIGA-NETO, 2020).

Veiga-Neto (2020) em sinergia com o posicionamento da comissão do The Lancet reitera a necessidade de pensarmos-agirmos o atual contexto pandêmico sob a perspectiva do enfrentamento de, na verdade, uma sindemia. Para ele, “... referir-se à pandemia covídica como uma sindemia é interessante, importante e potente, na medida em que acentua o seu caráter extremamente polimórfico e complexo (p. 10). Sendo assim, o autor passa a usar a expressão "sindemia covídica".

Os sistemas alimentares seguem, portanto, assumindo um papel central também no contexto da sindemia covídica, já que neste fenômeno as co-morbidades associadas à máalimentação - que por sua vez, se conectam com as questões ambientais, sociais, culturais, econômicas e políticas - são letais e potencializam os efeitos devastadores ocasionados tanto pela sindemia global, como pela sindemia covídica. Corroborando esses achados científicos o documento do Banco Mundial (2020) caracteriza o continente da ALeC como sendo a região que mais sofre com a chamada "carga tripla da má-nutrição", definida como sendo a confluência da 
desnutrição, sobrepeso e obesidade, assim como as deficiências de micronutrientes. Segundo esta referência

\begin{abstract}
Nas populações da ALeC se observa o maior índice de sobrepeso do mundo, e as deficiências de micronutrientes tem contribuído para o aumento das doenças associadas à alimentação, que frequentemente se refletem nas Doenças Crônicas Não Transmissíveis (DCNT), como as doenças cardiovasculares, diabetes tipo 2, derrames cerebrais e alguns tipos de cânceres de localização específica. A morbidade e a mortalidade associadas à má-alimentação seguirá aumentando na região, a menos que os padrões de conduta sejam alterados caminhando no sentido de um consumo alimentar saudável e para tanto, se exigem transformações, tanto por parte de quem consome, mas também de ações mais eficientes por parte de quem produz, já que a não disponibilidade de alimentos nutritivos é, supostamente, um grande obstáculo também (BANCO MUNDIAL, p. 06).
\end{abstract}

Outro relatório da EAT-Lancet (2020) - uma subcomissão do The Lancet -, também argumenta que são os atuais sistemas alimentares de produção industrial predatórios e destrutivos que vem, ao longo das últimas décadas, potencializando os fenômenos causadores do colapso da saúde das pessoas e do ambiente.

Para Rob Wallace (2020) a crise sanitária pela qual estamos passando possui uma relação direta com a expansão do sistema alimentar de produção industrial que, por sua vez se caracteriza pelo rastro de destruição que deixa aonde chega e/ou por onde passa. Para este autor, a redução dos habitats naturais ocasionada pelas devastações dos biomas para a expansão agrícola e pecuária certamente levarão o mundo a experimentar outras crises. Este autor, também evidencia que “... apesar de diferentes em suas particularidades os circuitos locais de produção operam por meio da mesma rede de expropriação global, com impactos ambientais subjacentes” (p. 529). Nestes termos, ao incorporar os princípios da Agroecologia nos níveis locais e territoriais é possível disparar processos mais críticos-reflexivos-problematizadores que contribuam, também, para as mudanças de atitudes frente algumas práticas cotidianas e assim, passar a operar em prol na construção de outras relações entre si, para e com a natureza abordando o conceito ampliado de saúde (ambiental, física, emocional e alimentar).

Ao fazer referência à interação necessária entre agroecologia e saúde parafraseamos “... propomos que uma poderosa oportunidade para uma ciência inovadora no campo em desenvolvimento da agroecologia seja a incorporação da saúde humana" (O'ROURKE, DELONGE, SALVADOR, 2017, pg. 19). Ainda para estes autores e autoras,

[...] ao adotar os objetivos de produtividade podemos ter assumido, involuntariamente, uma perspectiva limitada sobre o escopo de potenciais soluções, dando maior ênfase na produção calorias em vez de refeições 
adequadamente nutritivas e acessíveis, em condições ambientais seguras que são, possivelmente, mais importantes para um futuro sustentável (p. 19).

Sob a ótica do Direito Humano à Alimentação Adequada/DHAA, bem como da promoção da alimentação saudável (aqui referida como Comida de Verdade) e, portanto, da saúde, a agroecologia se conecta com as concepções do campo da Saúde Coletiva. Para Burigo e Porto (2019, p. 250) "O diálogo entre saúde e agroecologia também desperta questões epistemológicas que colocam em xeque paradigmas ainda hegemônicos na saúde coletiva”.

As autoras Giordani, Bezerra e Anjos (2017) em um ensaio reflexivo, mas trazendo constatações empíricas, sobre a relação do produzir-comer agroecológico afirmam que esta relação oportuniza acionar diferentes redes de sentidos “... como a integração e a dependência do espaço e o conceito ampliado de saúde que envolve um bem-estar que se completa na tomada de consciência em relação à necessidade de integração sociedade-natureza” (p. 434).

De fato, é algo mais complexo do que parece. Não basta a escolha individual por adotar uma alimentação composta apenas por alimentos saudáveis e/ou agroecológicos. Não se trata de saber ou não escolher. São questões que passam pelas dimensões da vida em sociedade (individual e coletiva). Passam também pelas esferas públicas e privadas.

Públicas mediante as ações políticas com vieses econômicos quando, por exemplo, se investe de forma desproporcional na ampliação do setor produtivo (seja na produção industrial com a isenção de impostos para a construção de plantas das fábricas e indústrias que por sua vez, desmatam biomas, seja na abertura de novas fronteiras agrícolas e pecuária, ou ainda com a aprovação de novas substâncias tóxicas para o uso na produção intensiva de grãos voltados à exportação, por exemplo).

Enquanto os investimentos que são necessários para conduzir processos voltados ao bem coletivo, mediante as políticas públicas que prezem pelo bem comum e social, sobretudo àquelas voltadas ao fortalecimento SUS, ou ainda a reforma agrária visando o acesso à terra para a produção de alimentos saudáveis, ações de incentivo à produção orgânica e/ou agroecológica, ou ainda àquelas que pautam a aquisição de alimentos locais e regionais como alimentação escolar entre outras, são ínfimas ou quase inexistentes, sendo que no contexto atual, 2020 a 2021, algumas dessas ações beiram cair no esquecimento. Urge ainda debater (e criar mecanismos para transformar) sobre os sistemas alimentares sustentáveis e saudáveis serem construídos e fortalecidos sob a perspectiva interseccional que tratem das questões de gênero, raça/etnia e classe social.

As questões também se inserem na esfera da vida privada. E trazem consigo outras variáveis que podem/devem ser tratadas (também na dimensão da vida pública), mas que tenham 
concretude no nível doméstico. Mencionam-se como exemplo, as dimensões do cuidado - e aqui damos ênfase à comida, como o mais concreto ato de cuidar (de si e as/os demais). Mais uma vez, apontamos a Agroecologia como sendo o caminho a ser trilhado para promover o enfrentamento às sindemias em curso, bem como as que estão por vir. Dos temas da vida cotidiana, de ser/estar, qual seria aquele que poderia impulsionar o refletir-agir-transformar que não a comida? Por isso, reiteramos as palavras de Giordani, Bezerra e Anjos (2017, p. 439) quando afirmam

[...] a agroecologia implica uma profunda transformação na relação com o ambiente, ao envolver um sistema de produção que renova os significados dos elementos da natureza, a energia e as várias dimensões do sistema, acaba igualmente por produzir diversos outros sentidos acerca do alimento. Dessa maneira, a alimentação resgata e reflete uma ligação primordial do ser humano com a natureza e sua posição genuína de dependência e cuidado para com o planeta - aciona redes de sentido, não restrita à sua função nutricional, sendo essa até mesmo dilatada pela noção do bem e bom comer.

Para Miles, DeLonge e Carlisle (2017, p. 18) “... o avanço da agroecologia e dos sistemas alimentares sustentáveis depende, em parte, de investimentos em pesquisa, bem como de cuidadosa consideração de fatores sociais, políticos e culturais". Porém, não podemos negligenciar que muitos dos investimentos em pesquisa dos chamados sistemas alimentares de produção industrial também disputam o campo das narrativas e das concepções "do saudável (e do sustentável)". Um exemplo dessa assertiva é o projeto BIOFort - liderado aqui no Brasil pela Empresa Brasileira de Pesquisa Agropecuária/ Embrapa. Essa tecnologia se caracteriza pela manipulação genética de determinados alimentos de modo a alterar seus genes interferindo assim na quantidade produzida de algum (ou alguns) micronutrientes. Segundo a Embrapa - o argumento é o sempre o mesmo - "diminuir a desnutrição e garantir maior segurança alimentar através do aumento dos teores de ferro, zinco e vitamina A na dieta da população mais carente" (EMBRAPA, 2011).

Nessas disputas contínuas, a Agroecologia no seu papel de construtora do conhecimento a partir do seu tripé ciência-movimento-prática é a que tenciona. Tenciona os debates dentro e fora da academia, assim como as pesquisas científicas. Tenciona os movimentos e, por fim, tenciona as práticas. Como mencionam Bezerra e colaboradores (2019, p. 14):

[...] a agroecologia tem o desafio de promover abordagens cada vez mais integradas, onde seja possível visualizar ações que cuidem da saúde ao mesmo tempo em que garantem a integridade ambiental e a equidade social, apontado pelos estudos como um dos requisitos básicos para construção e valorização dos sistemas alimentares sustentáveis. 
Segundo o relatório IPES-Food (2017) Global Alliance for the Future of Food (Aliança Global pelo Futuro da Alimentação), para que possamos vislumbrar sistemas alimentares verdadeiramente saudáveis, é preciso construir de forma contínua e intensa a partir das distintas esferas sociais, uma abordagem "mais integrada, multifacetada e holística, incluindo assim nutrição, saúde, felicidade e indicadores sociais e culturais". Tem-se, portanto, uma centralidade em torno da alimentação e nutrição como causas-e-consequências diretas dos sistemas alimentares sustentáveis e saudáveis, mesmo tendo a compreensão de que estes não são os únicos temas. Nesse sentido, a Agroecologia também estimula processos dialógicos que trazem em essência as dimensões da sustentabilidade e da saudabilidade já que esta se insere na dimensão da vida em sociedade que nos alinha à natureza e aos seus ciclos.

\section{Algumas considerações}

As reflexões primeiras, seguem nos motivando também no final. Reiteramos que os sistemas alimentares neoliberais seguem, de maneira absurda, colapsando a saúde humana e, mais ainda da natureza. Assim, refletir como podemos agir-transformar em prol da construção e/ou do fortalecimento de sistemas alimentares sustentáveis e saudáveis passa por ações individuais, coletivas, mas, sobretudo políticas.

Reiteramos ainda que, os processos sindêmicos - pelas pandemias associadas em si de desnutrição, sobrepeso/obesidade, mudanças climáticas e, mais recentemente a sanitária causada pela Covid-19 - pelos quais estamos vivendo, sofrendo e sentindo, de fato, desvela uma fissura social crônica, onde as desigualdades de acesso e de oportunidade (ou a falta de tudo mesmo) aparecem com mais força e intensidade quando fazemos os recortes de classe, gênero e raça.

Nesse caos instaurado em nível planetário, é nos territórios - comunidades rurais, urbanas, periféricas, aldeias indígenas, quilombolas, entre outras - onde a Agroecologia surge forte, pulsante, solidária. A agroecologia se faz presente a partir das mentes/mãos de quem constrói o conhecimento, planta, colhe, distribui, comercializa, alimenta e nutre, nos fazendo perceber que a construção de uma outra lógica vai além de promover sistemas alimentares locais, eles precisam ser também ambientalmente, culturalmente e socialmente sustentáveis.

Por fim reiteramos que, conhecer os sistemas alimentares neoliberais e a forma como estes operam seu poder destrutivo, bem como reconhecer outros sistemas que se apresentam como alternativas é determinante para apreender/praticar a Ciência da Nutrição. Nesse movimento é fundamental, portanto, compreender que a construção (criação/manutenção e/ou fortalecimento) de sistemas alimentares sustentáveis e saudáveis passa pelo compromisso ético do ser/estar/atuar como nutricionista e, neste percurso a participação em organizações da sociedade civil, 
associações, sindicatos, grupos e/ou coletivos, bem como instâncias de controle social como conselhos (municipais, estaduais e nacionais) é um oxigênio necessário para seguirmos a caminhada em prol de uma saúde integrada entre natureza e sociedade.

\section{Referências}

ABRASCO. Dossiê ABRASCO: um alerta sobre os impactos dos agrotóxicos na saúde. Org. CARNEIRO, F. F; AUGUSTO, L.G. S; RIGOTTO, R. M; FRIEDRICH, K; BÚRIGO, A. C. Rio de Janeiro: EPSJV. São Paulo. Expressão Popular, 2015.

ALEXANDRATOS, N.; BRUINSMA, J. World agriculture towards 2030/2050: The revision. ESA Working Paper n. 12-03, Rome: FAO, 2012.

AMORIM, S. T. S. P; MOREIRA, H; CARRARO, T. E. A formação de pediatras e nutricionistas: a dimensão humana. Revista de Nutrição. 14(2):111-118, 2001.

BANCO MUNDIAL - Banco Internacional de Reconstrucción y Fomento. Panoramas alimentarios futuros. Reimaginando la agricultura en América Latina y el Caribe. $1818 \mathrm{H}$ Street NW. Washington DC 20433. 2020.

BEZERRA, Islandia. SOUSA, Romier; LONDRES, Flávia; MONTEIRO, Denis. APRESENTAÇÃO ANA E ABA-AGROECOLOGIA. Cultivando diálogos e convergências: colhendo saúde e agroecologia. In: Caderno de estudos: saúde e agroecologia. org: BURIGO, André Campos. Et all. vol. 1. Rio de Janeiro: FIOCRUZ: ANA: ABA-Agroecologia, 2019.

BRASIL. Lei $n^{\circ} 11.346$ de 15 de setembro de 2006. Cria o Sistema Nacional de Segurança Alimentar e Nutricional (SISAN) com vistas em assegurar o direito humano à alimentação adequada e dá outras providências. Diário Oficial da União 18 set. 2006.

. Ministério da Saúde. Secretaria de Atenção à Saúde. Departamento de Atenção Básica.

Guia alimentar para a população brasileira. 2. Ed. Brasília, 2014. Disponível: https://bvsms.saude.gov.br/bvs/publicacoes/guia_alimentar_populacao_brasileira_2ed.pdf.

Acesso em: 20 nov. 2020.

Ministério da Saúde. Vigitel Brasil 2018: vigilância de fatores de risco e proteção para doenças crônicas por inquérito telefônico : estimativas sobre frequência e distribuição sociodemográfica de fatores de risco e proteção para doenças crônicas nas capitais dos 26 estados brasileiros e no Distrito Federal em 2019. Brasília: Ministério da Saúde. Brasília: DF, 2019. Disponível em: https://portalarquivos2.saude.gov.br/images/pdf/2019/julho/25/vigitel-brasil2018.pdf. Acesso em: 20 nov. 2020.

Ministério da Saúde. Secretaria de Vigilância em Saúde. Departamento de Análise em Saúde e Vigilância de Doenças Não Transmissíveis. Vigitel Brasil 2019 : vigilância de fatores de risco e proteção para doenças crônicas por inquérito telefônico : estimativas sobre frequência e distribuição sociodemográfica de fatores de risco e proteção para doenças crônicas nas capitais dos 26 estados brasileiros e no Distrito Federal em 2019. Brasília: DF, 2020. Disponível em: http://bvsms.saude.gov.br/bvs/publicacoes/vigitel_brasil_2019_vigilancia_fatores_risco.pdf.

Acesso em: 20 nov. 2020. 
BURIGO, André Campos; PORTO, Marcelo Firpo de Souza. Trajetórias e aproximações entre a saúde coletiva e a agroecologia. Saúde debate. Rio de Janeiro, v. 43, n. spe 8, p. 248-262, 2019. Available from $\quad$ http://www.scielo.br/scielo.php?script=sci_arttext\&pid=S0103$\underline{11042019001300248 \& \operatorname{lng}=\mathrm{en} \& \mathrm{nrm}=\text { iso }}$

CALÇAS, I. R. R; GIANLUPI, K; MISSIO, L; ALVARENGA, M. R. M. A formação do nutricionista sob a perspectiva do currículo em saúde. Interfaces da Educação, Paranaíba, v.7, n.19, p.361-375, 2016.

CONSELHO FEDERAL DE NUTRICIONISTAS - CFN. Código de Ética e de Conduta do Nutricionista. Princípios Fundamentais. 2018. Disponível em: https://www.cfn.org.br/wpcontent/uploads/2018/04/codigo-de-etica.pdf. Acesso em: jan. 2021.

DAVIS, J. H; GOLDBERG, R. A. A Concepto f Agribusiness, Harvard University. 1957.

DEVAUX, M; SASSI, F; CHURCH, J; CECCHINI, M; BORGONOVI, F. Exploring the Relationship Between Education and Obesity. OECD Journal: Economic Studies. 1, 2011. Disponível em: http://dx.doi.org/10.1787/eco_studies-2011-5kg5825v1k23. Acesso em: 29 nov. 2020.

EAT-Lancet Commission. Food in The Anthropocene: the EAT-Lancet Commission on Healthy Diets From Sustainable Food Systems. 2020.

FOOD AND AGRICULTURE ORGANIZATION OF THE UNITED NATIONS - FAO. International Fund For Agricultural Developmente, Unicef. World Food Programme. World Health Organization. The State Of Food Security And Nutrition In The Word. 2020. Disponível em: http://www.fao.org/3/ca9692en/online/ca9692en.html\#chapter-1_3. Acesso em: set. 2020.

FRIEDMANN, H. International political economy of food: a global crisis. New left Review, 197, jan./feb., p.29-57, 1993.

FRIEDMANN, H. From Colonialism to Green Capitalism: Social Movements and the Emergence of Food Regimes. In: BUTTEL, F. H; McMICHAEL, P. (Eds.). New Directions in the Sociology of Global Decelopment. Oxford: Elsevier, v.11, 2005.

EMBRAPA - Empresa Brasileira de Pesquisa Agropecuária. Resultados das ações de desenvolvimento de produtos nos projetos AgroSalud e BioFORT. Disponível em: https://ainfo.cnptia.embrapa.br/digital/bitstream/item/61508/1/2011-255.pdf

GIORDANI, R.; BEZERRA, I.; DOS ANJOS, M. de C. Semeando agroecologia e colhendo nutrição: Rumo ao bem e bom Comer. In: SAMBUICHI, R. H. R.O.; MOURA, I. F. D. O.; MATTOS, L. M. D. O.; ÁVILA, M. L. D. O.; SPÍNOLA, P. A. C. O.; SILVA, A. P. M. D. O. (Orgs.). A Política Nacional de Agroecologia e Produção Orgânica no Brasil: uma trajetória de luta pelo desenvolvimento rural sustentável. Brasília: Ipea, 2017.

GRUPO ETC. Tecno-fusiones comestibles: mapa del poder corporativo em la cadena alimentaria, classificación de empresas por sector e ingressos en 2018. noviembre, 2019. 
INSTITUTO BRASILEIRO DE GEOGRAFIA E ESTATÍSTICA - IBGE. Coordenação de Trabalho e Rendimento. Pesquisa de Orçamentos Familiares: 2017-2018: Análise da Segurança Alimentar no Brasil. Rio de Janeiro, 2020a.

Coordenação de Trabalho e Rendimento. Pesquisa de Orçamentos Familiares: 20172018: Avaliação Nutricional da Disponibilidade Domiciliar de Alimentos no Brasil. Rio de Janeiro, 2020b.

LOUZADA, M. L. D. C.; CANELLA, D. S.; JAIME, P. C.; MONTEIRO, C. A. Ali-mentação e saúde: a fundamentação científica do Guia Alimentar para a Popu-lação Brasileira. São Paulo: Faculdade de Saúde Pública da USP, 2019.

MANIFESTO da $5^{\text {a }}$ Conferência Nacional de Segurança Alimentar e Nutricional à Sociedade Brasileira sobre Comida de Verdade no Campo e na Cidade, por Direitos e Soberania Alimentar. 2015. Disponível em: https://www.abrasco.org.br/site/wpcontent/uploads/2017/06/copy2_of_Manifesto_comidadeverdade.pdf

McMICHAEL, P. Regimes Alimentares e Questões Agrárias. Tradução Midori, S. 1.ed. São Paulo; Porto Alegre: Editora Unesp; Editora da UFRGS, 2016.

MILES, A.; DELONGE, M. S.; CARLISLE, L. 2017. Triggering a positive research and policy feedback cycle to support a transition to agroecology and sustainable food systems, Agroecology and Sustainable Food Systems, 41:7, 855-879.

MULLER, G. Complexo agroindustrial e modernização agrária, ed. Hucitec. São Paulo. 1989.

NESTLE, M. Uma Verdade Indigesta: como a indústria alimentícia manipula a ciência do que comemos. Tradução de MENZEN, H. São Paulo: Editora Elefante, 2019.

NICHOLLS, Clara Inés. Prefácio. In: BARRENO, Richard Intriago; GARGALL Laura Saura. Agroecologia: ciência, práctica y movimiento para alcanzar la Soberanía Alimentaria. EDEC (Empresa de Desarrollo Económico de Cuenca) y SOCLA (Sociedad Científica Latinoamericana de Agroecología). 2020.

ODEVEZA, J. Entenda porque a isenção fiscal de agrotóxicos é o "incentivo" que mais desfavorece o Brasil. Terra de Direitos. 26 jun. Disponível em: https://terradedireitos.org.br/noticias/noticias/entenda-porque-a-isencao-fiscal-de-agrotoxicos-eo-incentivo-que-mais-desfavorece-o-brasil/23110. Acesso em: 15 set. 2020.

ORGANIZAÇÃO PANAMERICANA DE LA SALUD - OPS. ORGANIZAÇÃO MUNDIAL DE LA SALUD - OMS. Alimentos y bebidas ultraprocesados en América Latina: ventas, fuentes, perfiles de nutrientes e implicaciones. Whashington, DC, 2019.

OTERO, G; PECHLANER, P; GÜRCAN, E. C. The Neoliberal Diet: Fattening Profit and People. The Routledge Handbook of Poverty in the United States. Edited H. S. N; H. M. V; M. R. J. 2015.

PECHLANER, G; OTERO, G. The Neoliberal Food Regime: Neoregulation and the New Division of Labor in North Americar. Rural Sociology, 75(2), 2010. 
O'ROURKE, Megan E.; DELONGE Marcia S.; SALVADOR, Ricardo Insights from agroecology and a critical next step: Integrating human health, Agroecology and Sustainable Food Systems, 41:7, 880-884. 2017. Disponível em:

https://www.tandfonline.com/doi/full/10.1080/21683565.2017.1326073

PAULA, Nilson Maciel de. Evolução do sistema agroalimentar mundial: contradições e desafios. Curitiba: CRV, 2017. 2017.

PLOEG, J. D. Camponeses e impérios alimentares: lutas por autonomia e sustentabilidade na era da globalização. Tradução PEREIRA, R. Porto Alegre: Editora da UFRGS, 2008.

POULAIN, J. P. Sociologias da alimentação: os comedores e o espaço social alimentar. Trad. PROENÇA, R. P. C; RIAL, C. S; CONTE, J. Florianópolis: Ed. da UFSC. 2.ed. 2013.

TELLES, L. Desvelando a economia invisível das agricultoras agroecológicas: a experiência das mulheres de Barra do Turvo, SP. Dissertação (Mestrado em Extensão Rural) - Universidade Federal de Viçosa, Viçosa, 2018.

SCHMITT Cláudia; MONTEIRO, Denis; LONDRES, Flávia; PACHECO, Maria Emília; BROCHARDT, Viviane. AGROECOLOGIA NO BRASIL: AGROECOLOGIA NO BRASIL Valorizando as dimensões da ciência, das práticas, dos movimentos sociais e das inovações institucionais. In: ATLAS DO AGRONEGÓCIO: fatos e números sobre as corporações que controlam o que comemos. (org) SANTOS Maureen; GLASS, Verena. Rio de Janeiro: Fundação Heinrich Böll, 2018.

SOARES, W. L; PORTO, M. F. S. Uso de agrotóxicos e impactos econômicos sobre a saúde. Revista de Saúde Pública, 46(2):209-17, 2012.

SWINBURN, B. A. et al. A Sindemia Global da Obesidade, da Desnutrição e das Mudanças Climáticas: o relatório da Comissão The Lancet. Lancet, 2019. Acessado em: Fevereiro de 2021: https://alimentandopoliticas.org.br/wp-content/uploads/2019/08/idec-the lancetsumario_executivo-baixa.pdf

VEIGA-NETO, Alfredo. Mais uma Lição: sindemia covídica e educação. Educ. Real., Porto Alegre , v. 45, n. 4, e109337, 2020 . Disponível em $<$ http://www.scielo.br/scielo.php?script=sci_arttext\&pid=S217562362020000400203\&lng=pt\&nrm=iso $>$. acessos em 18 fev. 2021. Epub 11-Jan2021. https://doi.org/10.1590/2175-6236109337.

WALLACE, Rob. Pandemia e agronegócio: doenças infecciosas, capitalismo e ciência. Edição: Elefante \& Igra Kniga. 2020.

Recebido em 10/11/2020 - Aprovado em 24/01/2021 